\title{
Effect of Conservative Treatment for Refracture in Cemented Vertebrae After Percutaneous Vertebroplasty: A Long Term Follow-up
}

\author{
Jing Wang*, Min Chen, Jiang Du \\ Department of Orthopedics, the First Affiliated Hospital of Jinan University, Guangzhou, China
}

Email address:

twjing@jnu.edu.cn (Jing Wang)

*Corresponding author

\section{To cite this article:}

Jing Wang, Min Chen, Jiang Du. Effect of Conservative Treatment for Refracture in Cemented Vertebrae After Percutaneous Vertebroplasty: A Long Term Follow-up. Clinical Medicine Research. Vol. 5, No. 3, 2016, pp. 20-23. doi: 10.11648/j.cmr.20160503.11

Received: March 15, 2016; Accepted: April 5, 2016; Published: April 26, 2016

\begin{abstract}
By a long term follow-up, we evaluated the effects of conservative treatment for refracture of cemented vertebrae after percutaneous vertebroplasty (PVP). 12 patients of 324 patients who underwent PVP from January 2012 to August 2014, with back pain, were confirmed refracture in cemented vertebrae. 7 patients got conservative treatment: the usage of analgesics, osteoporosis medication, brace and physical therapy. Visual analogue seale (VAS) and Oswestry disability index (ODI) were evaluated at 7 days, 1,3 and 12 months after treatment. Patients were followed up for $21.3 \pm 11.2$ months. Compared with that before treatment, VAS and ODI scores were significantly decreased after treatment $(\mathrm{P}<0.05)$. VAS and ODI scores were also decreased significantly among 7 days, 1 and 3 months after treatment $(\mathrm{P}<0.05)$. No remarkable difference was found between 3 and 12 month $(\mathrm{P}>0.05)$. Further, there were no complications happened, such as leg phlebothrombosis, decubitus and hypostatic pneumonia. Thus, the results of our conservative treatment were optimal. Accordingly, the ratio of refracture in cemented vertebrae after PVP is low, but it is critical for back pain after PVP which should be pay enough attention for clinicians. Conservative treatment can relieve pain and improve spine function, without obvious complications.
\end{abstract}

Keywords: Percutaneous Vertebroplasty, Refracture in Cemented Vertebrae, Conservative Treatment, Long Term Follow-up

\section{Introduction}

Osteoporotic vertebral compression fractures (OVCFs) is common among elder people [1]. OVCFs cause pain, spinal deformity and dysfunction, which become a major issue that affecting public health of elderly population [2]. Percutaneous vertebroplasty (PVP), because of its advantage of minimally invasive and rapid pain relief, becomes the usual operative method for clinical treatment of painful OVCFs [3, 4]. Along with the widespread application and increasing cases of PVP, the postoperative recurrence of back pain is increasing yearly, the reason of which is due to the new compression fractures of adjacent vertebrae $[5,6]$. The increasing risk of adjacent vertebral fractures after PVP is confirmed by many studies, which aroused great attention of clinicians [7]. Accordingly, there are also refractures of cemented vertebrae after PVP, of which the ratio is low with afferent statistical data [8, 9]. By using visual analog scale (VAS) and Oswestry disability indexes (ODI) at different time points and by observing complications such as phlebothrombosis of leg, decubitus and hypostatic pneumonia, we evaluated the clinical curative effect and safety of conservative treatment for refracture in cemented vertebrae after PVP.

\section{Materials and methods}

\subsection{Subject Selection}

12 (14 vertebrae) patients of 324(381 vertebrae) patients of OVCFs who underwent PVP from January 2012 to August 2014, with back pain again were confirmed refracture in cemented vertebrae. 7 cases $(9$ vertebrae $)$ received conservative treatment. All patients were female, aged from $60-78$ (70.9 \pm 6.3$)$. The happening time of recurrence of refracture is $2-20(8 \pm 6.7)$ weeks after first PVP. The pain of patients was relieved after first PVP, the VAS score at 7 days 
was $1.0 \pm 0.5$ and ODI was $8.4 \% \pm 1.6 \%$.

\subsection{Inclusion and Exclusion Criteria}

Inclusion criteria: (1) After PVP, symptoms of OVCFs of older patients were relieved or disappeared, but later back pain reoccurred at the same position and activity was restricted; (2) lateral X-ray imaginings showed reduced postoperative vertebral height, larger than $1 \mathrm{~mm}$; (3) MRI confirmed, cemented vertebrae showed bone marrow edema, T1-weighted images showed weaker signals, T2-weighted images showed stronger signals around bone cement (Figure 1), compression fractures of adjacent vertebrae were excluded. Exclusion criteria: (1) Pathological vertebral fractures induced by cancer and etc.; (2) Bacterial infectious spondylitis and spinal cord or nerve root injury caused by PVP puncture; (3) Back pain induced by other reasons.
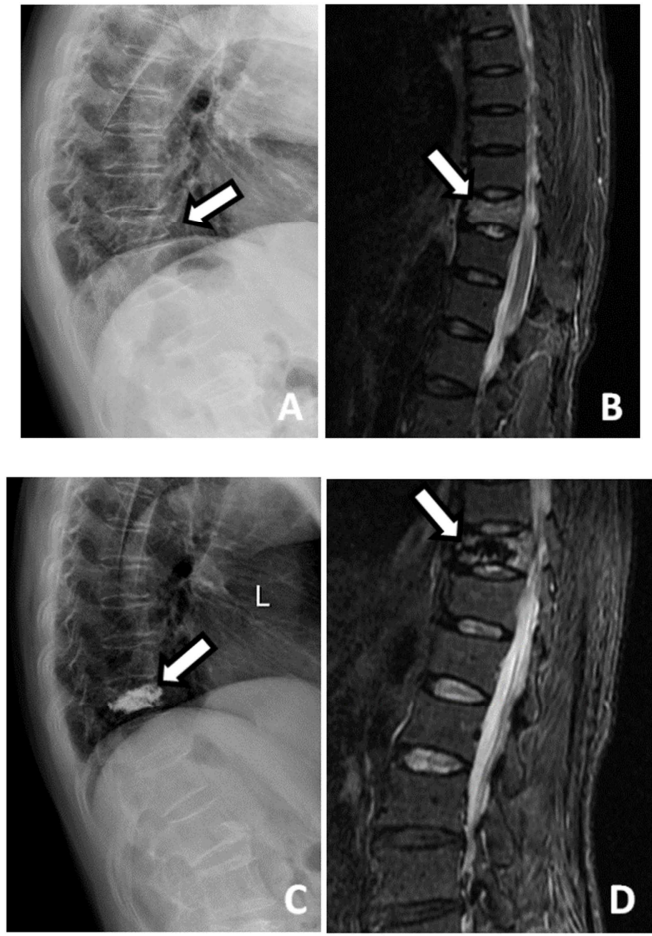

Figure 1. $T_{10}$ vertebrae refracture after $P V P$

(A) X-ray showed compression fracture of $\mathrm{T}_{10}$ vertebrae before PVP.

(B) Thoracic vertebra MRI: $\mathrm{T}_{2} \mathrm{WI}$ showed bone marrow edema and compression fracture in $\mathrm{T}_{10}$ vertebrae.

(C) The height of $\mathrm{T}_{10}$ vertebrae restored.

(D) Back pain recurred 2 weeks after PVP, Thoracic vertebra MRI: $\mathrm{T}_{2} \mathrm{WI}$ showed refracture in $\mathrm{T}_{10}$ vertebrae.

\subsection{Treatment}

Medical treatment: Loxoprofen sodium, eperisone hydrochloride and salmon calcitonin nasal spray for 3 weeks; Calcium and active vitamin D for 6 months. Bracing protection and functional exercise: bed rest for three weeks, wear back brace according to the pain situation, patients were encouraged to take back muscle and lower limb muscle training.

\subsection{Clinical Follow-up and Evaluation Methods}

Telephone follow-up or clinic referral 7 days, 1, 3 and 12 month after the treatment, record the pain VAS, ODI values and whether complications of leg phlebothrombosis, decubitus and hypostatic pneumonia happened.

\subsection{Statistical Analysis}

SPSS 18.0 (PASW, Statistics, IBM) were used to analyze the data. Data were presented as $\bar{x} \pm s$. Comparison of values of VAS and ODI before and after treatment were analyzed by repeated measures ANOVA. Comparison of values within different time points were analyzed by Bonferroni t-test. $\mathrm{P}<0.05$ was considered significant.

\section{Results}

The number of OVCFs patients that received PVP was 324 (381 vertebrae), among which 12 cases (14 vertebrae) showed refracture of cemented vertebrae, the ratio was $3.7 \%$. 7 cases $(9$ vertebrae) received conservative treatment, the general data of which were shown in Table 1. All seven patients were followed up ranging from 13 to 29 months $(21.3 \pm 11.2)$. No complications such as leg phlebothrombosis, decubitus and hypostatic pneumonia happened. The values of VAS and ODI after conservative treatment were decreased significantly (Table 2 ). VAS score and ODI percentage were also decreased significantly among 7 days, 1 and 3 months after treatment $(\mathrm{P}<$ $0.05)$. However, no remarkable difference $(P>0.05)$ was found between 3 and 12 month. Average VAS score was $8.3 \pm 0.8$ before treatment, $3.1 \pm 1.2$ at 1-month follow-up and $0.8 \pm 0.7$ at 3-month follow-up. Average ODI percentage was $88.3 \% \pm$ $3.2 \%$ before treatment, $56.3 \% \pm 7.7 \%$ at 1 -month follow-up and $5.9 \% \pm 2.8 \% 3$-month follow-up (Table 2).

Table 1. Clinical data of patients with refracture in cemented vertebrae after PVP.

\begin{tabular}{lllllll}
\hline $\mathbf{n}$ & Gender & Age(year) & The first fracture vertebrae & Refracture vertebrae & Time of refracture (week) & Complication \\
\hline 1 & female & 75 & T7, T10, L3 & T10, L3 & 2 & no \\
2 & female & 6 & T10 & T10 & 4 & no \\
3 & female & 65 & T12, L1 & L1 & 3 & no \\
4 & female & 71 & L1, L4 & L1, L4 & no & no \\
5 & female & 78 & T11, L1 & L1 & 4 & no \\
6 & female & 75 & T7 & T7 & 20 & no \\
7 & female & 72 & L1 & L1 & \\
\hline
\end{tabular}


Table 2. Compared with the score of VAS and ODI before and after treatment ( $\bar{x} \pm s)$.

\begin{tabular}{|c|c|c|c|c|c|c|}
\hline Index & Before treatment & $\begin{array}{l}7 \text { days after } \\
\text { treatment }\end{array}$ & $\begin{array}{l}1 \text { months after } \\
\text { treatment }\end{array}$ & $\begin{array}{l}3 \text { months after } \\
\text { treatment }\end{array}$ & $\begin{array}{l}12 \text { months after } \\
\text { treatment }\end{array}$ & Statistic \\
\hline $\begin{array}{l}\text { VAS (Score) } \\
P=0.003\end{array}$ & $8.3 \pm 0.8$ & $6.9 \pm 0.9$ & $3.1 \pm 1.2$ & $0.8 \pm 0.7$ & $0.7 \pm 0.5$ & $\mathrm{~F}=42.452$ \\
\hline $\begin{array}{l}\text { ODI }(\%) \\
\mathrm{P}=0.000\end{array}$ & $87.9 \pm 3.9$ & - & $56.3 \pm 7.7$ & $5.9 \pm 2.8$ & $4.5 \pm 2.2$ & $\mathrm{~F}=1136.84$ \\
\hline
\end{tabular}

Note: "-" means no record

\section{Discussion}

Vertebral compression fractures are the most common fractures among osteoporosis population [10]. For a long time, none-surgical treatments including bed rest, pain medications, brace protection and back muscle exercise are the only alternative for patients of OVCFs with no neural symptoms. Because of its advantages of minimally invasive and rapid pain relief, the application of PVP changed the curing concept of OVCFs $[11,12]$. The short and long term follow-ups all showed excellent effects [13-15]. But as the widespread usage of PVP, the back pain post operation gradually attracted people's attention. After PVP, the risk ratio of adjacent vertebrae fracture increases, which is the usual cause of back pain after PVP [6]. Recently, cemented vertebrae after PVP also showed refracture, with varied but low ratio $[7,8]$. There are many treatments for adjacent vertebrae refracture after PVP, such as another PVP or some other open spine surgeries [9]. Until now, we cannot conclude the best option for the treatment of refracture after PVP because of the few cases. From Jan 2012 to Aug 2014, we used conservative treatment for the refracture after PVP and found that conservative treatment can efficiently relieve the pain and induce functional recovery, with no complications.

Conservative treatment of OVCFs including: (1) pain relief and functional recovery excise, such as all kinds of excise under pain medication, bed rest and bracing protection; (2) evaluate and cure future osteoporosis. Back pain is the main primary complaints of patients with cemented vertebrae refractures, thus pain relief is especially important. Relieving pain can improve the life quality and bring comfort, and can also promote their early recovery excise. Nonsteroidal anti-inflammatory drugs (NSAIDs) are proved as first-line drugs for back pain relief [16]. Paraspinal muscle relaxant is beneficial to relieve pain caused by muscle spasm. It can enhance the effect of NSAIDs by stop the vicious circle between pain induced by OVCFs and paraspinal muscle spasm [17]. So, we used combined drug prescription with NSAIDs and paraspinal muscle relaxant.

The application of brace is a landmark in the conservative treatment of spinal vertebral compression fractures. The biggest role of brace is to keep the stability of the spine during movement, thus the use of brace can mitigate the pain due to spinal instability. Brace equipment can maintain normal physiological curvature of the spine, limit flexion, reduce the axial load of fractured vertebrae and restrict the progress of convex deformity [18]. Thus, during the conservative treatment of no matter acute OVCFs or none OVCFs, brace is recommended [19]. To elder patients, light and soft brace is suggested [20]. We used common waistline with dorsal support, which can guarantee the basic painless activities at relative early ambulation.

In summary, by a long-term follow-up, we found that conservative treatment of patients with cemented vertebrae refracture after PVP is effective and safe. Because of the low ratio of this refractures, the sample size in the current study is rather small. We are gathering more cases in the future to enlarge the sample size to conclude more accurate conclusion.

\section{References}

[1] Wang, D., W. X. Dai, J. Feng, C. Ma, and D. H. Wu, [Efficacy evaluation of percutaneous vertebroplasty via an extra-pedicular approach for osteoporotic compression fracture]. Zhonghua Yi Xue Za Zhi, 2013, 93(11): 845-8.

[2] Tang, H., J. Zhao, and C. Hao, Osteoporotic vertebral compression fractures: surgery versus non-operative management. J Int Med Res, 2011, 39(4): 1438-47.

[3] Huang, H., S. He, W. Fang, H. Zhu, J. Guo, G. Deng, G. Zhu, Y. Qin, and G. Teng, [Percutaneous vertebroplasty for treatment of painful osteoporotic vertebral compression fractures: a retrospective analysis of clinical efficacy]. Zhonghua Yi Xue Za Zhi, 2014, 94(27): 2119-22.

[4] Li, Y. A., C. L. Lin, M. C. Chang, C. L. Liu, T. H. Chen, and S. C. Lai, Subsequent vertebral fracture after vertebroplasty: incidence and analysis of risk factors. Spine (Phila Pa 1976), 2012, 37(3): 179-83.

[5] Blasco, J., A. Martinez-Ferrer, J. Macho, L. San Roman, J. Pomes, J. Carrasco, A. Monegal, N. Guanabens, and P. Peris, Effect of vertebroplasty on pain relief, quality of life, and the incidence of new vertebral fractures: a 12-month randomized follow-up, controlled trial. J Bone Miner Res, 2012, 27(5): 1159-66.

[6] Ahn, Y., J. H. Lee, H. Y. Lee, S. H. Lee, and S. H. Keem, Predictive factors for subsequent vertebral fracture after percutaneous vertebroplasty. J Neurosurg Spine, 2008, 9(2): 129-36.

[7] Heo, D. H., D. K. Chin, Y. S. Yoon, and S. U. Kuh, Recollapse of previous vertebral compression fracture after percutaneous vertebroplasty. Osteoporos Int, 2009, 20(3): 473-80.

[8] He, S. C., G. J. Teng, G. Deng, W. Fang, J. H. Guo, G. Y. Zhu, and G. Z. Li, Repeat vertebroplasty for unrelieved pain at previously treated vertebral levels with osteoporotic vertebral compression fractures. Spine (Phila Pa 1976), 2008, 33(6): 640-7. 
[9] Chiu, Y. C., S. C. Yang, H. S. Chen, Y. H. Kao, Y. K. Tu, and K.C. Chung, Clinical evaluation of repeat percutaneous vertebroplasty for symptomatic cemented vertebrae. J Spinal Disord Tech, 2012, 25(8): E245-53.

[10] Guo, J. B., Y. Zhu, B. L. Chen, B. Xie, W. Y. Zhang, Y. J. Yang, Y. S. Yue, and X. Q. Wang, Surgical versus non-surgical treatment for vertebral compression fracture with osteopenia: a systematic review and meta-analysis. PLoS One, 2015, 10(5): e0127145.

[11] Chang, X., Y. F. Lv, B. Chen, H. Y. Li, X. B. Han, K. Yang, W. Zhang, Y. Zhou, and C. Q. Li, Vertebroplasty versus kyphoplasty in osteoporotic vertebral compression fracture: a meta-analysis of prospective comparative studies. Int Orthop, 2015, 39(3): 491-500.

[12] Shengzhong, M., W. Dongjin, W. Shiqing, S. Yang, R. Peng, M. Wanli, and G. Chunzheng, Modification of percutaneous vertebroplasty for painful old osteoporotic vertebral compression fracture in the elderly: preliminary report. Injury, 2012, 43(4): 486-9.

[13] Ma, X. L., D. Xing, J. X. Ma, W. G. Xu, J. Wang, and Y. Chen, Balloon kyphoplasty versus percutaneous vertebroplasty in treating osteoporotic vertebral compression fracture: grading the evidence through a systematic review and meta-analysis. Eur Spine J, 2012, 21(9): 1844-59.

[14] Huang, Z., S. Wan, L. Ning, and S. Han, Is unilateral kyphoplasty as effective and safe as bilateral kyphoplasties for osteoporotic vertebral compression fractures? A meta-analysis. Clin Orthop Relat Res, 2014, 472(9): 2833-42.

[15] Chen, H., P. Tang, Y. Zhao, Y. Gao, and Y. Wang, Unilateral versus bilateral balloon kyphoplasty in the treatment of osteoporotic vertebral compression fractures. Orthopedics, 2014, 37(9): e828-35.

[16] Kearney, P. M., C. Baigent, J. Godwin, H. Halls, J. R. Emberson, and C. Patrono, Do selective cyclo-oxygenase-2 inhibitors and traditional non-steroidal anti-inflammatory drugs increase the risk of atherothrombosis? Meta-analysis of randomised trials. $B M J, 2006,332$ (7553): 1302-8.

[17] Browning, R., J. L. Jackson, and P. G. O'Malley, Cyclobenzaprine and back pain: a meta-analysis. Arch Intern Med, 2001, 161(13): 1613-20.

[18] Wong, C. C. and M. J. McGirt, Vertebral compression fractures: a review of current management and multimodal therapy. $J$ Multidiscip Healthc, 2013, 6: 205-14.

[19] Dai, L. Y., L. S. Jiang, and S. D. Jiang, Conservative treatment of thoracolumbar burst fractures: a long-term follow-up results with special reference to the load sharing classification. Spine (Phila Pa 1976), 2008, 33(23): 2536-44.

[20] Gnanenthiran, S. R., S. Adie, and I. A. Harris, Nonoperative versus operative treatment for thoracolumbar burst fractures without neurologic deficit: a meta-analysis. Clin Orthop Relat Res, 2012, 470(2): 567-77. 